\title{
Plano de Logística Sustentável - PLS: um estudo comparativo em Universidades Federais da Região Metropolitana de São Paulo
}

\section{Sustainable Logistics Plan - PLS: a comparative study in Federal Universities of the Metropolitan Region of São Paulo}

\author{
RAQUEL DA SILVA PEREIRA* \\ GEBEL EDUARDO MENDONÇA BARBOSA **
}

\section{RESUMO}

Desde a Convenção Internacional Rio+20 (2012), o Brasil avançou em termos de desenvolvimento sustentável, publicando o Decreto Federal no. 7.746/2012, que determina a implementação de um Plano de Logística Sustentável (PLS) em órgãos públicos federais. Nesse contexto, enquadram-se as Universidades Federais. Assim, nesta pesquisa objetivou-se analisar e comparar os PLS de Universidades Federais na Região Metropolitana de São Paulo (RMSP): da Universidade Federal do ABC (UFABC) e da Universidade Federal de São Paulo (UNIFESP), evidenciando semelhanças e diferenças entre eles. Utilizou-se estudo de cunho qualitativo e exploratório, com pesquisa documental, consubstanciada por entrevistas com pessoas diretamente envolvidas na elaboração dos respectivos planos. Os dados foram analisados sob a ótica da análise de conteúdo. Os resultados permitem concluir que, apesar de a base normativa ser única quanto ao direcionamento construtivo do PLS, os referidos Institutos de Ensino Superior-IES adotaram formas distintas na orientação,

* Universidade Municipal de São Caetano do Sul. Professora do Programa de Pós-graduação em Administração da USCS. raquelspereira@uscs.edu.br .

** USCS. Universidade Municipal de São Caetano do Sul. Mestrando em Administração na USCS. gebel.eduardo@gmail.com . 
estruturação e composição de esforços para a consecução do referido Plano.

Palavras-chave: Desenvolvimento sustentável. Gestão ambiental. Plano de logística sustentável. Universidade.

\section{Abstract}

Since on the International Convention Rio+20 (2012), Brazil has advanced in terms of sustainable development, publishing Federal Decree no. 7.746 / 2012, which determines an implementation of a Sustainable Logistics Plan (PLS) in federal public agencies. In this context they are classified as Federal Universities. Thus, this research aimed to analyze and compare the PLS of Federal Universities in the Metropolitan Region of São Paulo (RMSP): Federal University of $A B C$ (UFABC) and Federal University of São Paulo (UNIFESP), evidencing. A qualitative and exploratory study was used, with documental research, based on interviews with the involved people involved in the elaboration of the treatments. The data were analyzed from the perspective of the content analysis. The results conclude that, although a normative basis is as important as the constructive orientation of the PLS, theses Institutes of Higher Education (IHE) have adopted different forms in the orientation, structuring and composition of efforts to achieve said Plan.

Key-words: Sustainable development. Environmental management. Sustainable logistics plan. University.

\section{INTRODUÇÃo}

A dinâmica social contemporânea configura-se por uma série de estímulos que refletem a necessidade de mudança nos campos político, social, econômico e ambiental, haja vista os movimentos internacionais, entre esses os que questionam a forma de interação entre sociedade e meio ambiente.

A publicação do relatório "The limits to growth", em 1972, pelo Clube de Roma, a partir da avaliação de especialistas à época, evidenciou o impacto negativo do vertiginoso crescimento populacional sobre os recursos naturais. O documento sugere uma mudança radical no modelo de produção e consumo, a fim de mitigar seus efeitos futuros e danosos de escassez desses recursos (HOGAN; 
MARANDOLA; OJIMA, 2010). Desde então, o modelo de produção e consumo moderno, passou a ser questionado quanto à sua sustentabilidade no longo prazo, constituindo-se um desafio bastante atual.

A partir da publicação do Relatório Brundtland, em 1987, o conceito de desenvolvimento sustentável promoveu as bases para uma proposta mais equitativa na relação consumerista, para que seja ambientalmente sustentável (PNUMA, 2001).

Dessa forma, as organizações públicas, privadas e do terceiro setor esforçam-se para uma atuação que possa privilegiar o necessário desenvolvimento sustentável, que considere ao menos três dimensões básicas de sustentabilidade: a econômica, a social e a ambiental (ELKINGTON, 2001).

Cabe ainda observar que, sendo as organizações um grupo social sustentado por políticas, tecnologias, processos, pessoas e cultura própria, observa-se um funcionamento sistêmico que obedece a determinadas regras, entre elas as emanadas pelas legislações.

Entretanto, quanto ao aspecto de observação normativa pelas organizações, a atuação dos gestores de organizações privadas difere das organizações públicas, sendo que nas primeiras é permitido fazer tudo que a lei não veda, já quanto às últimas, tem sua atuação circunscrita ao que a lei autoriza realizar (MEIRELLES, 2005).

Diante desse cenário, e considerando o significativo papel exercido pelos órgãos públicos na materialização dos programas governamentais e, portanto, evidenciando-se como destacado ator social e administrativo na busca e difusão por novas formas de atuação sustentável, foi publicado, no âmbito federal, em 2012, o Decreto $n^{\circ}$. 7.746 (BRASIL, 2012a), que regulamentou o artigo $3^{\circ}$. da Lei n⿳o. 8.666, de 21 de junho de 1993 (BRASIL, 1993), estabelecendo a obrigatoriedade de elaboração de um Plano de Logística Sustentável (PLS) pelos órgãos públicos federais.

Após a publicação do referido Decreto, o Ministério do Planejamento, Orçamento e Gestão editou a Instrução Normativa $n^{\circ}$. 10 (IN nº. 10), de 12 de novembro de 2012 (BRASIL, 2012b), com a finalidade de orientar a elaboração do PLS.

Entre os órgãos da administração pública federal estão as Universidades Federais, às quais compete observar a elaboração dos seus respectivos planos e, por se tratar de assunto relevante e 
bastante recente, justifica-se a investigação acerca de tais planos e de sua implementação por esses centros educacionais.

Citando a experiência de Sharp (2009, p. 1, tradução do autor), que cursava uma universidade australiana, em 1992, deparando-se diante de um dilema, ou seja, por um lado enquanto era ensinado nos bancos acadêmicos o rápido esgotamento dos sistemas de suporte à vida planetária, por outro, constatava, entre outros, que as luzes das salas de aula ficavam acesas mesmo quando vazias, herbicidas eram usados nos jardins do campus e caminhões que ali trafegavam exalavam fumaça preta de diesel. A partir de então, ele se indagava "se as universidades não mudassem, então, quem poderia e quem iria...?"

Assim, evidenciou-se o seguinte problema a ser investigado nesta pesquisa: Como as universidades federais se estruturaram para conceber seus Planos de Logística Sustentável (PLS)?

Para tanto, optou-se por um estudo comparativo entre duas universidades federais no âmbito da Região Metropolitana de São Paulo (RMSP): a Universidade Federal do ABC (UFABC) e a Universidade Federal de São Paulo (UNIFESP).

Objetivou-se verificar como se deu a elaboração e a implantação dos PLS nas referidas universidades.

\section{REFERENCIAL TEÓRICO}

O conceito de desenvolvimento sustentável apresentado pelo Relatório Brundtland, em 1987, sob o aspecto de tempo e espaço, estabeleceu uma "justiça intergeracional" com relação à adequada utilização dos recursos naturais pela sociedade do presente, de forma a não comprometer as necessidades das gerações vindouras (ARAGÃO, 2012).

As mudanças ocorridas no mercado, no ambiente tecnológico e de negócios, transformam as organizações. Da mesma forma, quando do surgimento dessas acabam também por influenciar a sociedade em geral, fazendo o papel das organizações passar a ter grande relevância e interesse social (BORGER, 2001).

Assim, o papel das organizações, dos governos e da sociedade civil com relação ao desenvolvimento sustentável, inseriu-se aos debates da Conferência das Nações Unidas sobre Meio Ambiente e 
Desenvolvimento, em 2012, na cidade do Rio de Janeiro, na Convenção Rio+20. Na oportunidade foram avaliados os compromissos firmados pela comunidade internacional, quando da realização de conferência anterior realizada, em 1992, a Rio 92, envolvendo temas relacionados aos desafios ambientais, sociais e econômicos.

\subsection{Rio+20 como marco de orientação normativa da administração federal sustentável}

A realização da Conferência Rio+20 estabeleceu um novo marco após vinte anos da Conferência das Nações Unidas sobre Meio Ambiente e Desenvolvimento realizada, em 1992, na cidade do Rio de Janeiro, a Rio 92, sendo que sua própria organização baseou-se na aquisição de materiais e serviços sustentáveis.

Para a viabilização de tal ação, foi publicado o Decreto Federal no. 7.746, de 5 de junho de 2012 (BRASIL, 2012a), que dispõe "sobre as compras públicas sustentáveis e consagrou o processo já conduzido pelo Comitê Nacional de Organização da Rio+20 de aquisição de produtos e serviços sustentáveis para a realização da Conferência Rio+20" (SOLLA, 2012, p. 23).

De acordo com Alencastro, Silva e Lopes (2014, p. 219):

A necessidade de incorporar critérios de sustentabilidade na condução dos processos licitatórios trouxe um novo desafio para o gestor público brasileiro que, historicamente, elaborou editais visando selecionar a proposta de menor valor, sem questionar as práticas socioambientais do fabricante ou do fornecedor dos bens e serviços.

Para orientar a Administração Federal quanto à adoção de práticas sustentáveis, o referido Decreto previu a elaboração do Plano de Logística Sustentável (PLS) pelos órgãos públicos federais, entretanto, tal plano foi caracterizado por meio da Instrução Normativa n⿳o. 10 (IN no .10 ), de 12 de novembro de 2012, sendo que seu artigo $3^{\circ}$. o define como:

...ferramenta de planejamento com objetivos e responsabilidades definidas, ações, metas, prazos de execução e mecanismos de monitoramento e avaliação, que permite ao órgão ou entidade estabelecer 
práticas de sustentabilidade e racionalização de gastos e processos na Administração Pública (BRASIL, 2012b).

Entretanto, em que pese a importância do encontro entre as diversas lideranças dos países-membros, o evento também promoveu um marco jurídico e administrativo para a materialização de práticas sustentáveis no âmbito da administração pública federal, com a edição do Decreto n⿳o. 7.746, de 5 de junho de 2012 (BRASIL, 2012a), normatizando o processo organizador do evento, por meio das compras públicas sustentáveis da Rio+20 (RIO+20, 2016).

Entre os órgãos pertencentes à administração pública federal, a educação tem papel singular, no que se refere à conscientização no exercício de práticas sustentáveis, pois, segundo o encontro promovido pela UNESCO a respeito da Educação para o Desenvolvimento Sustentável e o Papel da Agenda 2030, a diretora geral da entidade, Irina Bokova, destacou que "a educação é o fio condutor que liga a Agenda 2030 e o Acordo de Paris sobre o Clima" (UNESCO, 2016).

Assim, no que compete ao esforço educacional e de conscientização quanto às sociedades sustentáveis, as IES se deparam com um grande desafio imposto pelo desenvolvimento sustentável no século XXI, no qual, segundo a Associação de Líderes Universitários para um Futuro Sustentável (ULSF, 2008), tem-se a sustentabilidade como um foco crítico no ensino, na pesquisa, em suas próprias operações, e na sua divulgação.

Em consonância com tal posicionamento, Posner e Stuart (2013) expressam que as IES são atores sociais e exercem papéis na sociedade às quais estão inseridas, sendo que, como organizações, são promotoras de empregos, gerenciam recursos e geram resíduos, impactando o meio ambiente. Como local de aprendizagem e pesquisa, formam profissionais para a assimilação dos problemas ambientais, formulando estratégias e técnicas para solucioná-los. Além disso, promovem uma base de fomento na composição de políticas sociais que conduzam a comportamentos sociais mais sustentáveis.

Para Weenen (2000), a universidade possui três maneiras gerais para enfrentarem o desafio de mudança de paradigma para o desenvolvimento sustentável: 
1ํ. - abordagem "evolutiva”, na qual há um esforço preliminar de um processo de integração do desenvolvimento sustentável em toda a universidade;

$2^{\text {o. }}$ - abordagem "chave", na qual as pessoas e disciplinas estão centradas e majoritariamente motivadas naquilo que se espera para responderem ao desafio; e

$3^{\text {o. }}$ - abordagem "pioneira", no qual um contexto organizacional totalmente novo é percebido como potencialmente promissor e importante na contribuição para o desenvolvimento sustentável (WEENEN, 2000, p. 32, tradução do autor).

Ademais, para que as IES promovam e liderem mudanças para práticas sustentáveis, evitando comprometer a qualidade de vida das gerações futuras, seus profissionais devem estar bem preparados com relação ao desenvolvimento sustentável a fim de educar e formar jovens e adultos, promovendo mudanças para novos padrões socialmente sustentáveis (LOZANO et al., 2013).

\subsection{A logística como processo de apoio à sustentabilidade organizacional}

A busca por eficiência e maior produtividade são respostas organizacionais a um mercado altamente competitivo e inconstante. A logística é um importante elemento na estratégia organizacional, para a redução de custos e maior integração na gestão da cadeia de suprimentos, devendo ser sustentável, portanto, precisa estar contemplada na estratégia organizacional (ODA et al., 2009).

Farias et al. (2013) corroboram, afirmando que a logística sustentável coopera na configuração estratégica de agregação de valor, de modo a mitigar a utilização de matéria-prima e a emissão de poluentes, além de evidenciar a responsabilidade socioambiental e o surgimento de tecnologias limpas suprindo, assim, a sociedade e o mercado com bens e serviços sustentáveis. Essa proposição fortalece a ideia de economia circular, em que se deve reutilizar tudo o que for possível, evitando-se o descarte e a disposição final dos materiais.

No que diz respeito à representatividade da gestão pública de suprimentos na economia, segundo o Guia para Implementação de Compras Públicas Sustentáveis - Manual Procura+ (ICLEI, 2015), as 
aquisições de bens e serviços no primeiro setor econômico respondem por cerca de $18 \%$ a $30 \%$ do Produto Interno Bruto (PIB) nos países membros da Organização para a Cooperação e Desenvolvimento Econômico (OCDE).

Especificamente, no Brasil, as aquisições públicas, em 2012, representaram 21,5\% do PIB (ICLEI, 2015). Assim sendo, tais aquisições quando guiadas por esforço conjunto (ganhos de escala) a fim de se inserir em uma diretriz comum dentro dos ditames do desenvolvimento sustentável, podem representar forte vetor indutor de melhores práticas na cadeia de fornecimento de serviços e bens com baixo impacto ambiental, com maior eficiência econômica e, por conseguinte, proporcionar maior benefício social (SILVA; BARKY, 2012).

Para Monzoni, Biderman e Betiol (2006, p. 3), a licitação sustentável pode ser entendida como "uma solução para integrar considerações ambientais e sociais em todos os estágios do processo da compra e contratação dos órgãos governamentais com objetivo de reduzir impactos à saúde humana, ao meio-ambiente e aos direitos humanos".

A principal legislação para licitações e contratações na Administração Pública brasileira é a lei no․ 8.666/1993 (BRASIL, 1993), sendo que essa prevê em seu artigo 3o. a seleção de propostas mais vantajosas à administração e que, ao mesmo tempo, incentive o desenvolvimento sustentável.

Por sua vez, o Decreto $\mathrm{n}^{\circ}$. 7.746 regulamenta o referido artigo no âmbito federal e instituiu a Comissão Interministerial de Sustentabilidade na Administração Pública - CISAP, que propõe ações orientadas à logística sustentável, além de promover assessoria aos órgãos públicos federais para a sua consecução.

A IN no. 10 , por sua vez, regulamenta o referido Decreto flexibilizando a forma como as entidades podem compor seus PLS, podendo variar de acordo com as especificidades estruturais de cada órgão. Quando houver impedimento relacionado à infraestrutura física, quanto à adaptação de edifícios, esses órgãos deverão fundamentar tais inexecuções (BRASIL, 2012b).

A mesma instrução normativa determina que os órgãos devem instituir Comissão Gestora do Plano de Gestão de Logística Sustentável (CGPLS), composta por no mínimo três servidores que terão como atribuição elaborar, monitorar, avaliar e revisar o PLS, 
sendo que o acompanhamento dos resultados alcançados deverá ser publicado semestralmente no site do respectivo órgão, devendo, ao final de cada ano, publicar e encaminhar à CISAP balanço dos resultados alcançados e ações a serem desenvolvidas no ano subsequente (BRASIL, 2012b).

A IN no.10 também estabelece que minimamente os PLS devem tratar dos seguintes temas: material de consumo (ao menos, papel de impressão, copos descartáveis e cartuchos de impressão); energia elétrica; água e esgoto; coleta seletiva, qualidade de vida no ambiente de trabalho; compras e contratações sustentáveis e deslocamento de pessoal.

A partir destas considerações procurou-se investigar como as universidades federais na Região Metropolitana de São Paulo formularam os seus respectivos PLS e quais indicadores estabeleceram para a mensuração periódica.

\section{Metodologia}

A presente pesquisa é de abordagem qualitativa e do tipo exploratória, sendo que, segundo Gil (2002), esse tipo de pesquisa visa proporcionar maior conhecimento acerca do problema, sobretudo por se tratar de assunto bastante recente e com poucas publicações a respeito do tema.

Optou-se por um delineamento de pesquisa ancorado em estudo de casos, que permitiu comparar duas Universidades Federais no que diz respeito à elaboração do PLS, sendo que, de acordo com Yin (2001, p. 51), uma vez que "a base de conhecimento existente pode ser deficiente, e a literatura disponível não fornece nenhuma estrutura ou hipótese conceitual digna de nota", para a superação do problema proposto, justificando assim, o estudo de casos.

A coleta de dados ocorreu de duas formas: a primeira por meio documental, especialmente quanto ao conteúdo dos PLS publicados pelas referidas Universidades e a realização de levantamento das legislações correlatas ao tema de pesquisa. A segunda forma foi por intermédio de entrevistas com duas pessoas diretamente envolvidas na elaboração dos referidos planos, as quais tiveram a responsabilidade de coordenação dos trabalhos, tanto na UFABC, como na UNIFESP. 
Para a realização das entrevistas, elaborou-se previamente uma pauta de temas desenvolvidos a partir do referencial teórico. O desenvolvimento dos temas orbitou pelos oito pontos mínimos exigidos pela IN no‥ 10, quais sejam: Material de Consumo, Energia Elétrica, Água e Esgoto, Coleta Seletiva, Qualidade de Vida no Ambiente de trabalho, Material de Consumo, Mobilidade, Compras e Contratações.

Tanto na análise documental, quanto nas entrevistas realizadas foi aplicada a técnica de análise de conteúdo das comunicações estabelecidas, entendendo essas como sendo:

...um conjunto de técnicas de análise das comunicações visando obter, por procedimentos sistemáticos e objectivos de descrição do conteúdo das mensagens, indicadores (quantitativos ou não) que permitam a inferência de conhecimentos relativos às condições de produção/recepção (variáveis inferidas) destas mensagens (BARDIN, 2004, p. 37).

Bardin (2004, p. 40) esclarece que o processamento da informação documental visa "dar forma conveniente e representar de outro modo essa informação" facilitando sua compreensão.

As entrevistas foram transcritas e validadas pelos entrevistados em ambas as instituições, pois Vergara (2016, p. 52-53) recomenda que "depois de transcrevê-la, apresente a transcrição ao entrevistado, para que confirme ou faça alterações que julgar necessárias".

O conteúdo dos PLS e das entrevistas teve seus elementos submetidos a processo de categorização, o que permitiu aprimorar a forma de análise (BARDIN, 2004).

Chegou-se a um agrupamento de oito categorias que, por sua vez, permitiram organizar o que se buscava na investigação, quais sejam: Planejamento e estruturação do trabalho; Capacitação de pessoal para a elaboração do plano; Composição e articulação com atores internos e externos; Estruturas e ações ambientais existentes; Encaminhamento e desenvolvimento dos trabalhos; Valores evidenciados com a instituição do PLS; Dificuldades e desafios encontrados, além da Existência de resultados alcançados até então.

Esse conjunto de técnicas foi utilizado para o estudo profundo de comunicações feitas pelas Universidades que se encontram no es- 
copo desta pesquisa. A análise minuciosa dos conteúdos informados nos PLS publicados pelas respectivas instituições foi fundamental para que se evidenciassem as diferenças e semelhanças existentes entre seus conteúdos e, ao mesmo tempo, revelaram um pouco da cultura dessas organizações.

Para Bardin (2004, p. 27), trata-se de um conjunto de possibilidades a serem utilizadas em um "único instrumento" que permite adaptação de formas, possibilitando a investigação e a compreensão de fenômenos por meio da observação do conteúdo da mensagem escrita ou falada.

\section{RESUlTAdo E DisCUSSÃo}

\subsection{Análise dos dados sob a perspectiva documental}

A seguir, são descritas as características formais de cada um dos PLS publicados pelas Universidades.

\subsubsection{O PLS da Universidade Federal de São Paulo - UNIFESP}

A UNIFESP é uma instituição pública do governo federal, tendo sua origem na Escola Paulista de Medicina, fundada em 1933, passando por processo de federalização em 1956 e possui os seguintes campi: Baixada Santista, Diadema, Guarulhos, Osasco, São José dos Campos e São Paulo, que engloba o prédio da Reitoria e o complexo hospitalar São Paulo, totalizando aproximadamente 23.500 alunos e 55 cursos de graduação (UNIFESP, 2015, 2016a, 2016b).

O Plano de Logística Sustentável da UNIFESP foi publicado em setembro de 2015, tendo sido elaborado por uma Comissão nomeada por portaria interna (Portaria no ${ }^{\circ} .4 .444$, de 12/12/2014), composta por servidores da Reitoria, dos campi da universidade e do Hospital, a qual é responsável pelo monitoramento, avaliação e revisão do plano, tendo como foco a responsabilidade socioambiental, promovendo a contribuição da instituição para o desenvolvimento sustentável (UNIFESP, 2015).

A finalidade declarada no respectivo PLS é de implementar a cultura da sustentabilidade na Instituição, assim, além de se suportar nas diretrizes emanadas pelo Decreto $\mathrm{n}^{\circ}$. 7.746 , propõe-se a: 
- Aplicar a Política de Excelência em Sustentabilidade na UNIFESP (PENSA-UNIFESP);

- Aplicar a Política de Gerenciamento de Resíduos Sólidos da UNIFESP (PRS-UNIFESP);

- Divulgar a Política dos 5R's (Reduzir, Repensar, Reaproveitar, Reciclar e Recusar);

- Estimular a adoção de práticas de consumo sustentável;

- Divulgar as normas ligadas à sustentabilidade com o propósito de que sejam mais conhecidas e seguidas; e

- Adequar as ações realizadas na UNIFESP para que sigam requisitos de sustentabilidade (UNIFESP, 2015).

No que concerne à elaboração do PLS, a universidade operacionalizou suas atividades de elaboração por meio da construção de instrumento norteador denominado Check-list, ou seja, configurou planilha eletrônica com doze tópicos, cada um em uma aba, a saber: Instruções; Diagnóstico; Temas; Exemplo de Plano de Ação (PA); um PA para cada um dos sete objetivos estratégicos traçados e Capacitação.

Quanto aos PAs, esses se estabeleceram em torno dos seguintes temas: Material de consumo; Energia elétrica; Água e geração de esgoto; Coleta seletiva; Qualidade de vida no ambiente de trabalho; Uso da frota de veículos; Eficiência em processos departamentais; Processos de compras e contratações (UNIFESP, 2015).

Para o acompanhamento do PLS, a Universidade prevê dinâmica de melhoria contínua por meio de um processo ancorado em um ciclo PDCA (Plan, Do, Check e Act), com revisão anual do PLS de modo a aperfeiçoá-lo, além de possibilitar a inserção de novas propostas de ação.

Dessa forma, a elaboração do PLS na UNIFESP tem como objetivo geral "a implementação de práticas de sustentabilidade e racionalização de gastos e processos na Administração Pública" (UNIFESP, 2015, p. 19). Os objetivos específicos declarados são:

- Inserção da responsabilidade socioambiental nas atividades da UNIFESP;

- Promover a boa gestão de recursos e eficiência do gasto público, considerando atributos de sustentabilidade, reduzindo custos e combatendo desperdícios; 
- Adotar critérios de sustentabilidade ambientais nas compras públicas, induzindo o mercado a adotar padrões de produção pautados em protocolos ambientais;

- Promover ações de sensibilização e capacitação dos servidores (UNIFESP, 2015, p. 20).

\subsubsection{O PLS da Universidade Federal do ABC - UFABC}

A UFABC é uma instituição pública do governo federal localizada na região do Grande $A B C$, tendo iniciado suas atividades em 2006 e possui atualmente dois campi: Santo André e São Bernardo do Campo, totalizando aproximadamente 13 mil alunos e 25 cursos de graduação (UFABC, 2016).

O PLS da UFABC foi publicado em 2015 e teve seu início com a instituição da CGPLS por meio da publicação da portaria interna (Portaria $n^{\circ}$. 80, de 6 de fevereiro de 2015) composta de servidores de distintas áreas do conhecimento, a qual possuía a atribuição de coordenação das atividades para elaboração do PLS (UFABC, 2015).

Segundo a citada Universidade, o PLS visa alinhar-se às práticas de sustentabilidade previstas em seu Plano de Desenvolvimento Institucional 2013-2022 (PDI), o qual, conforme Dias, Magalhães e Barbosa (2006, p. 1), tal plano tem por objetivo "definir a missão da instituição, metas, objetivos e estratégias para atingi-los, além de conter as diretrizes e políticas que irão nortear o desenvolvimento pretendido pela universidade", sendo que, no caso específico, procura uma interação com a sociedade de forma ativa, promovendo o desenvolvimento local e sustentável (UFABC, 2013, 2015).

Assim, o objetivo geral da Universidade na fase de formulação do PLS é elaborar "um plano de ações voltadas à formulação da Política de Sustentabilidade da Universidade Federal do ABC" (UFABC, 2015, p. 11).

Tendo como objetivos específicos:

- Diagnosticar as atividades sustentáveis já iniciadas, concluídas e em andamento na Universidade;

- Levantar as impressões que a comunidade universitária possui sobre o tema; 
- Estabelecer objetivos, metas, ações, indicadores de monitoramento, prazos e custos para cada eixo estudado;

- Desenvolver uma consciência coletiva de compromisso sustentável com os recursos disponíveis na Universidade;

- Incentivar a realização de pesquisas voltadas à sustentabilidade institucional;

- Promover qualidade de vida à comunidade universitária;

- Consolidar-se como uma Universidade Sustentável (UFABC, 2015, p. 11).

De forma geral, a metodologia adotada para a elaboração do respectivo PLS foi: estabelecer os eixos com seus conteúdos mínimos, convidar membros da comunidade universitária para composição da CGPLS, estabelecer matriz de objetivos para cada grupo de trabalho (GT), promover e desenvolver o I Fórum de Sustentabilidade da universidade para a construção do PLS, desenvolver atividades dos GTs com estabelecimento de metas, indicadores e pesquisas de opinião junto à comunidade universitária, coletar dados por meio de questionários aplicados a todos os gestores e dirigentes sobre iniciativas internas de sustentabilidade, elaborar documento base do PLS, realizar consulta pública acerca do referido documento, redigir o documento final, apresentar à Reitoria e publicar (UFABC, 2015).

No que se refere à organização de GTs, foram estabelecidos em número de sete, ou seja, um GT para cada eixo temático, a saber: Água e esgoto; Energia; Material de consumo e Licitações sustentáveis; Gerenciamento de resíduos; Espaços; Deslocamento de pessoal e Mobilidade urbana, além de Implementação e Divulgação. Cada GT/eixo estabeleceu objetivo a ser atingido, por meio da fixação de metas e ações a serem desenvolvidas em um horizonte de curto, médio e longo prazo (UFABC, 2015).

\subsection{Análise dos dados sob a perspectiva dos entrevistados}

Conforme disposto pela metodologia adotada, foram entrevistados os servidores diretamente envolvidos na condução, estruturação e operacionalização das atividades relacionadas à elaboração dos PLS na UNIFESP e UFABC, por meio de uma mesma pauta básica de temas previamente definidos com base no referencial teórico. 
As entrevistas ocorreram em outubro de 2016, sendo que a elaboração da pauta aplicada às entrevistas buscou compreender, sob uma ótica de cunho exploratória, como cada Universidade se estruturou, conduziu e se já é possível perceber alguma agregação de valor e resultado com a elaboração e instituição dos respectivos PLS.

A entrevista com a UNIFESP transcorreu por intermédio da Coordenação de sua CGPLS, a fim de compor elementos para o entendimento a respeito das questões já expostas, tendo como interlocutora a representante da Divisão de Sustentabilidade do Departamento de Gestão e Segurança Ambiental da Reitoria.

Na UFABC, a entrevista foi realizada com a Coordenação da CGPLS, a qual concedeu agenda de modo a compor elementos para o entendimento a respeito das questões já expostas, que orientam a presente pesquisa.

\subsubsection{Análise Comparativa}

Uma vez organizados os elementos constantes de ambas as entrevistas e aplicada análise de seu conteúdo, foram estabelecidas, por fim, oito categorias, passando-se à comparação dessas de acordo com os conteúdos expostos a respeito da dinâmica de formulação dos respectivos PLS nas universidades estudadas. Assim, foram constatados os seguintes pontos por categoria identificada:

a) Quanto ao Planejamento e Estruturação do Trabalho:

A UNIFESP construiu sinergia com estrutura já consolidada de seus campi, a respeito de gestão ambiental, uma vez que já existiam em todos os campi uma Divisão de Gestão Ambiental.

A composição da CGPLS foi formada por técnicos administrativos de todos os campi, sendo indicados pela Câmara Técnica de Gestão e Segurança Ambiental, tendo por atribuição a elaboração e o acompanhamento das ações propostas pelos campi para a composição de um único PLS.

Para que isso ocorresse, foi realizado um levantamento preliminar a partir do arcabouço normativo a respeito do assunto e feito um benchmarking com outros órgãos.

Foi também evidenciado no conteúdo da entrevista que alguns indicadores da Agenda Ambiental na Administração Pública (A3P) foram considerados na composição de seu plano. 
Para apoiar o planejamento das unidades (campi e Reitoria) que compõem a Universidade, foi desenvolvida uma planilha (checklist) como principal instrumento guia para o registro das ações, das metas que cada unidade deve atingir, com um cronograma de execução, estabelecendo assim um sistema interno e operacional de constituição de um repositório integrado de informações.

No que concerne à UFABC, a CGPLS foi instituída com uma composição heterogênea de perfis (professores e técnicos administrativos) com a colaboração de discentes, baseando-se nas competências individuais de seus membros, e tendo por missão inicial a formulação do PLS, sendo que a função de acompanhamento foi feita a posteriori, por meio da instituição de nova comissão.

A principal atitude revelada de conhecimento e propostas, para a construção do conteúdo para o PLS pela Comissão Gestora, foi, conforme declarado, a de "escutar" a comunidade universitária. Para tanto, GTs foram constituídos por eixo/tema, conforme a IN n ${ }^{\circ}$. 10, tendo como respectivas lideranças um membro de sua CGPLS.

Para o delineamento do plano, foi realizada pelos GTs um diagnóstico das informações setoriais e de atividades relacionadas à sustentabilidade já existentes na instituição, estabelecendo como prioridade a aquisição de materiais sustentáveis.

b) Quanto à Composição e Articulação com Atores Internos e Externos:

Em nenhuma das universidades foi constatada interação com a CISAP, sendo que a UNIFESP, de forma pontual, informou que enviou o seu PLS àquele órgão.

No que se refere à articulação com atores internos, na UNIFESP a Comissão de Gestão Ambiental de todos os campi indicou seus respectivos representantes para desenvolver as ações do PLS.

A UFABC, com o intuito de conhecer experiências acerca da gestão ambiental e práticas sustentáveis, promoveu evento intitulado "I Fórum de Sustentabilidade da UFABC", onde procurou conhecer práticas externas, por meio de representantes da Universidade de São Paulo e do Ministério do Meio Ambiente. 
c) Quanto às Estruturas e Ações Ambientais Existentes:

A UNIFESP, como já citado, já possuía nos campi estruturas de Gestão Ambiental e de Gestão e Segurança, sendo que essas estão funcionalmente integradas a cada um dos campi. Com o advento da CGPLS, foi estabelecido um vínculo de cunho técnico com aquelas estruturas.

Várias ações já eram exercidas localmente, com o apoio de sistemas do governo federal, como o ComprasNet (Portal de Compras do Governo Federal), o qual possui indicação se o material é sustentável ou não, bem como, o SisPes (Sistema Esplanada Sustentável), que é direcionado às despesas administrativas dos órgãos federais, incluindo aí o consumo de água e energia elétrica.

Além disso, já havia estímulos à práticas de incentivo a videoconferência com mitigação de reuniões presenciais, implantação de programa de ginástica laboral e área de convivência na unidade da Reitoria, aquisição de materiais eletrônicos com selo Procel - Programa Nacional de Conservação de Energia Elétrica - e Relatório de Sustentabilidade ancorado na estrutura GRI (Global Reporting Iniciative).

No caso da UFABC, já eram desenvolvidos o Programa de Coleta Seletiva, o tratamento de resíduos de laboratórios, grupos voltados a dinamizar os espaços universitários, de forma a promover uma saudável convivência e a utilização do SisPes para registrar o consumo de água e energia elétrica.

d) Quanto ao Encaminhamento e Desenvolvimento dos Trabalhos:

Nas entrevistas, evidenciou-se haver iniciativas isoladas de cunho sustentável nas Universidades estudadas, observando-se ausência de integração corporativa entre essas ações.

Na UNIFESP, a planilha (checklist), além de desempenhar papel de instrumento de orientação, captação e acompanhamento de ações realizadas em todos os campi, foi também um guia indutor de integração no desenvolvimento dessas ações pelos campi, sendo que, no caso da UFABC, buscou-se formalizar um documento que conjugasse as várias iniciativas e conhecimentos a respeito de ações sustentáveis dispersas nos campi.

Foram projetados, na UNIFESP, oito objetivos estratégicos com o intuito de orientar o desenvolvimento de práticas de sustentabili- 
dade com material de consumo, energia elétrica, água e geração de esgoto, coleta seletiva, qualidade de vida no ambiente de trabalho, compras e contratações, frota de veículos e eficiência nos processos departamentais.

Esses objetivos compuseram a planilha que, por sua vez, foi encaminhada para cada uma das unidades organizacionais (campi e Reitoria).

No que diz respeito ao "o quê" e "como" definir e detalhar as ações alinhadas a tais objetivos, ficou sob a autonomia de cada unidade organizacional, sendo que os planos de ação decorrentes são debatidos no ambiente da Câmara Técnica de Gestão Ambiental. Além disso, no que confere aos programas de conscientização e publicação do PLS, isso coube também a cada unidade.

A comunicação estabelecida pela UFABC para o desenvolvimento de seu PLS se deu por meio de pesquisas, entrevistas, correio eletrônico e realização de eventos, tendo sob a CGPLS uma capilaridade de linhas bidirecionais de informação com os GTs, às quais trafegavam demandas, orientações e resultados de levantamentos realizados, com reuniões periódicas estabelecidas pelo GT.

Dessa forma, a universidade procurou envolver a comunidade acadêmica no projeto, tendo sido estabelecido inicialmente uma metodologia de trabalho, composta por identificação dos eixos e respectivos conteúdos, arregimentação e composição de colaboradores para o projeto, estabelecimento de uma matriz de objetivos em cada GT, realização de Fórum de Sustentabilidade, desenvolvimento e acompanhamento de atividades dos GTs, aplicação de questionário a todos os setores e dirigentes, redação do documento preliminar do PLS para submissão em uma consulta pública, consolidação de propostas, redação final, apresentação à Reitoria e publicação em seu site institucional.

e) Quanto aos Valores Evidenciados com a Instituição do PLS:

Considerando a acepção de Nascimento et al. (2016), pode-se constatar, na análise de conteúdo da entrevista com a UNIFESP a respeito da implementação do seu PLS, maior integração e conhecimento de iniciativas isoladas, no que se refere à sustentabilidade no âmbito de suas unidades, com intensificação de troca de expe- 
riências entre os campi, maior relevância do papel exercido pelas equipes de apoio à gestão ambiental, além de inserção dos sistemas governamentais existentes como suporte ao alcance de metas estipuladas pelo plano.

Na UFABC, também foi constatado que o PLS atuou como indutor de iniciativas sustentáveis isoladas e que já estavam em desenvolvimento na instituição, promovendo oportunidade de interlocuções entre temas, como no caso aquisições sustentáveis e gerenciamento de resíduos. Outro aspecto evidente foi a ampliação do escopo proposto pela IN no . 10 de alguns temas mínimos, como energia elétrica, que foi ampliado e fixado institucionalmente com o tema "energia", contemplando, assim, outros tipos de energia, não somente a elétrica. $\mathrm{O}$ mesmo ocorreu com a coleta seletiva e qualidade de vida laboral, as quais foram ampliadas à dimensão mais ampla, sendo que no primeiro caso seu entendimento expandiu-se para o gerenciamento de resíduos, englobando o tratamento de rejeitos e resíduos laboratoriais, já no segundo caso, estendeu-se para uma perspectiva de lazer e convivência harmônica, com conforto ambiental.

\section{f) Quanto às Dificuldades e Desafios encontrados:}

Inicialmente, na UNIFESP, houve dificuldades de entendimento das propostas de elaboração do PLS por alguns campi, sendo que tais situações foram superadas por maior aproximação da CGPLS junto às diretorias desses campi.

O Hospital Universitário não integrou as ações de elaboração e consequente acompanhamento em face de suas especificidades com relação às demais unidades, bem como, no caso do regime de trabalho diferenciado existente do pessoal hospitalar.

No que se refere à movimentação de pessoal para colaborar na condução do PLS, também apontou dificuldades em razão de falta de pessoal nos campi, apesar de algumas realocações terem sido efetuadas.

Quanto ao inventário de materiais, dificuldades foram encontradas em função dos campi apresentarem distintas plataformas de sistemas que suportam tais informações, sendo que essas não indicavam se o material é ou não sustentável. 
Outra questão foi a restrição orçamentária para a promoção de ações sustentáveis e questões relativas às compras, no que se refere à decisão por aquisições de materiais mais sustentáveis ou de menor preço.

Além disso, foi relatada insensibilidade por parte de alguns discursos pontuais internos na adoção por uma iluminação sustentável e também dificuldades de mapear a dinâmica de iniciativas isoladas internas de projetos relacionados ao meio ambiente.

Na UFABC, por se tratar apenas do compromisso da CGPLS com a formulação do PLS, em um primeiro momento, dificuldades foram relatadas em função do tamanho e complexidade da instituição, no estabelecimento de canais para "escutar" pessoas de distintos conhecimentos e áreas, sendo concebido um documento resultante de um consenso possível e com ações factíveis.

Da mesma forma que na UNIFESP, a CGPLS da UFABC teve dificuldades com o tratamento do inventário quanto à identificação e classificação de materiais sustentáveis e no mapeamento da dinâmica de iniciativas isoladas a respeito do tema.

\section{g) Quanto à Existência de Resultados Alcançados:}

Foi possível constatar na UNIFESP, segundo os relatos, ações sustentáveis dos campi em torno de um único PLS com acompanhamento da CGPLS.

Entre tais ações, foram citadas a facilitação de um sistema de informação interno de troca de experiências e iniciativas entre suas unidades, maior integração com sistemas do governo federal (SisPes), o que possibilitou a detecção de vazamentos de água no campus Osasco, contratação de cooperativa para recolhimento de resíduos pelo campus Guarulhos, substituição de garrafas de água por bebedouros na Reitoria, a criação de um sistema interno de TI para a Gestão Ambiental para registro de informações relativas às ações descritas no PLS e consequente acompanhamento e realização do $1^{o}$. ciclo avaliativo, referente ao $1^{\mathfrak{o}}$. semestre de 2016.

Na UFABC, em que pese a recente publicação de seu PLS, já foi possível, segundo relato, verificar o início de trabalhos relativos ao eixo relacionado ao Deslocamento de Pessoal e Mobilidade Urbana, estabelecendo parceria com uma ONG para desenvolver alternati- 
vas sustentáveis de mobilidade de sua comunidade acadêmica, na busca de soluções integradas com o poder público local, além da percepção interna de já haver iniciativas de pesquisas relacionadas às ações descritas no seu plano.

h) Quanto à Capacitação de Pessoal para Elaboração do PLS:

Em nenhuma das instituições estudadas foram relatadas atividades específicas de capacitação de pessoal para a elaboração do PLS, apenas a promoção do "I Fórum de Sustentabilidade da UFABC" para sensibilização da comunidade acadêmica.

\subsection{Comparação Consolidada}

Considerando o delineamento teórico, segundo o qual dispõe sobre o papel das IES com relação ao desenvolvimento sustentável e explicitação do arcabouço normativo, o qual estabelece regras ao administrador público federal para a elaboração do PLS, construiu-se um quadro comparativo, a partir das categorias reveladas pela análise de conteúdo do cotejo dos PLS publicados pelas respectivas universidades e das entrevistas realizadas nas instituições pesquisadas. (Quadro 1).

Pode-se observar, analisando-se as oito categorias investigadas, baixa homogeneidade de categorias intermediárias, considerando-se que, apesar de o início da construção dos PLS ter partido de uma mesma instrução normativa, cada Universidade seguiu um delineamento, o que as levou a subcategorias diferentes, o que nesse momento de implantação dos referidos planos não pode ser avaliado em termos de resultados obtidos, o que poderá ser verificado alguns anos após a implantação.

\section{CONSIDERAÇões FINAIS}

É inegável a importância das IES na formação de profissionais e cidadãos quanto à incorporação de novos comportamentos e atitudes a respeito do desenvolvimento sustentável no modo de vida das pessoas, mas também é de igual importância a inserção dessas instituições com vistas a se constituírem em imensos laboratórios de práticas sustentáveis na sua própria gestão e em seus processos, pois, segundo Kalinowska e Batorczak (2015), as instituições de en- 


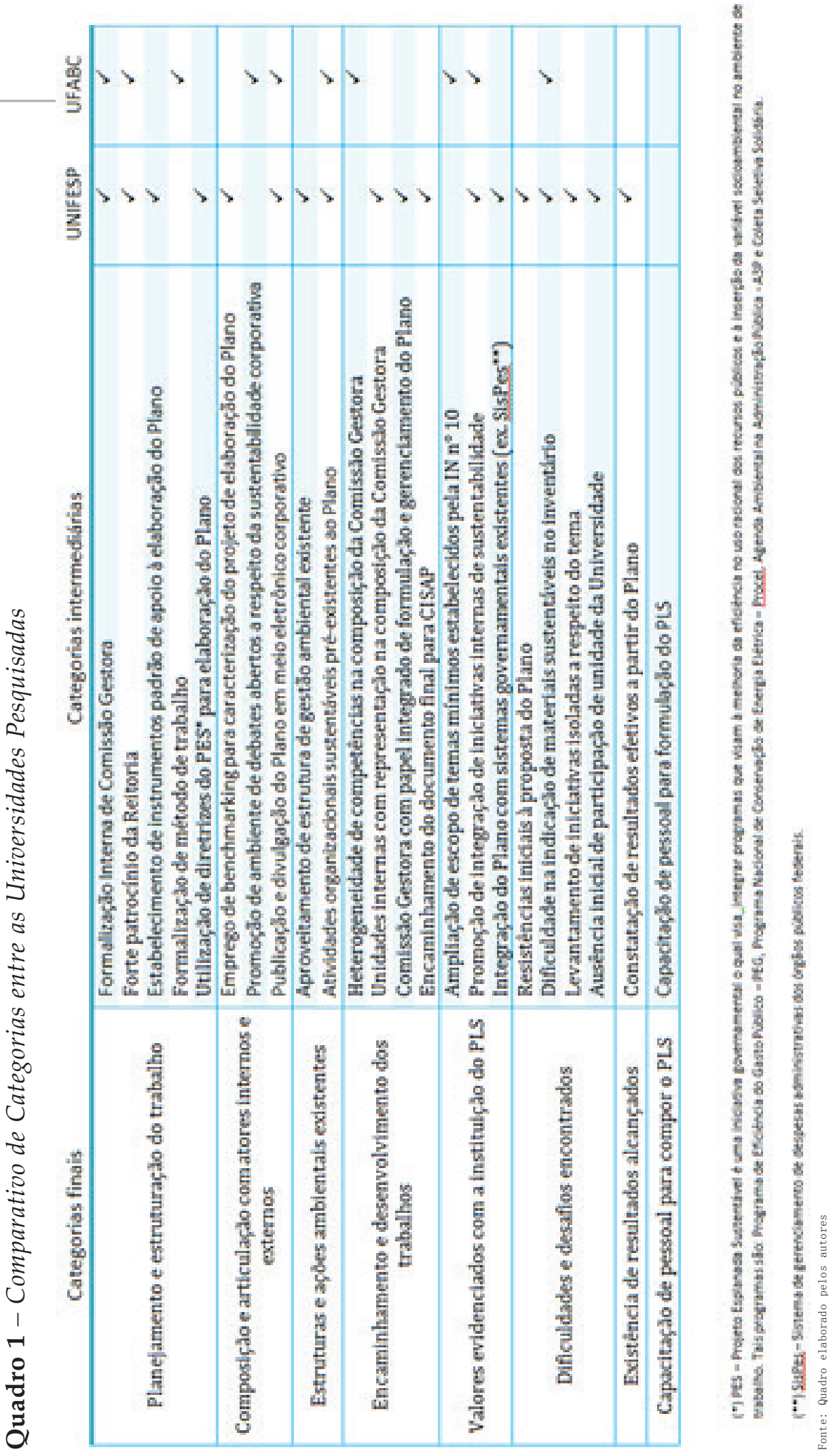


sino devem primeiro se transformar, reconhecendo que uma agenda de desenvolvimento sustentável exige mudança de paradigma na educação. Trata-se assim, de uma transformação e ampliação da responsabilidade institucional, bem como, uma revisão do currículo escolar e de sua pedagogia, de modo a atender às necessidades das gerações atuais e futuras.

Nesse aspecto, deve-se considerar que os esforços necessários para a sustentabilidade do campus universitário constituem desafio quanto à disponibilidade adequada de recursos para a implementação de ações a partir de avaliação e priorização de ações que devem ser executadas, considerando que as Universidades são sistemas complexos, nos quais o entendimento claro dos seus elementos estruturantes e de suas respectivas relações pode favorecer a identificação de pontos de alavancagem para a mudança de paradigma, buscando melhorias organizacionais quanto ao planejamento e gerenciamento de programas de sustentabilidade, potencializando grandes mudanças (POSNER e STUART, 2013, tradução do autor).

O PLS, por ser essencialmente ferramenta de planejamento, que permite à IES estabelecer práticas de sustentabilidade e racionalização de gastos, evidenciou durante a sua elaboração, em ambas as universidades estudadas, a existência de iniciativas ambientais isoladas nos campi que, segundo Posner e Stuart (2013, tradução do autor), entendem, de forma geral, que, embora tais iniciativas melhorem aspectos específicos no campus, apenas o desenvolvimento de esforços baseados em uma visão sistêmica do ensino superior conduz a uma sustentabilidade institucional sistêmica socioeconômico-ambiental.

Em ambas as universidades foram formalizadas suas Comissões Gestoras do PLS, entretanto, com atribuições distintas, pois na UNIFESP abordou-se a formulação e o próprio acompanhamento do PLS, enquanto que na UFABC apenas a fase de elaboração. Outro aspecto revelado foi quanto à composição dessa comissão, sendo que na UNIFESP foi composta essencialmente por técnicos administrativos e de representantes dos campi, Reitoria e Hospital Universitário, já na UFABC teve uma composição heterogênea de docentes e técnicos administrativos, com o apoio de discentes.

No que se refere à integração com sistemas governamentais existentes, a UNIFESP revelou tal interação inserida ao seu PLS. 
Cabe ainda relatar que a UFABC não se fixou nos temas mínimos propostos pela IN no. 10, mas ampliou o escopo de algumas dessas proposições temáticas, enquanto a UNIFESP evidenciou maior integração como trocas de práticas sustentáveis operacionalizadas em seus vários campi, além de ajustar processos internos quanto à inserção de atributo informacional de identificação de materiais sustentáveis em seu patrimônio.

Assim, à guisa de conclusão, esta pesquisa buscou contribuir com o conhecimento acadêmico por meio de investigação de como duas Universidades Públicas Federais de ensino superior da RMSP, se estruturaram para desenvolverem seus PLS, além de proporcionar bases para novas pesquisas a respeito da efetividade da aplicação dos PLS em Instituições Federais de Ensino Superior e em que medida tais instrumentos corroboram para a promoção de campi Universitários sustentáveis.

Como limitação da pesquisa reconhece-se a importância de continuidade, pesquisando-se outras IES e a forma de implementação de seus PLS, com acompanhamento longitudinal dessas ações.

\section{REFERÊNCIAS}

ALENCASTRO, Maria Alice Cruz; SILVA, Edson Vicente da; LOPES, Ana Maria D’ Ávila. Contratações sustentáveis na administração pública brasileira: a experiência do Poder Executivo federal. Revista de Administração Pública. Rio de Janeiro, v. 48, n. 1, 2014.

ARAGÃO, Alexandra. Direito Constitucional do Ambiente da União Europeia. In: CANOTILHO, José Joaquim Gomes; LEITE, José Rubens Morato (Orgs.). Direito Ambiental Constitucional Brasileiro, 5. ed. São Paulo: Saraiva, 2012.

BARDIN, Laurence. Análise de conteúdo, 3. ed. Lisboa: Edições 70, LDA. 2004.

BORGER, Fernanda Gabriela. Responsabilidade social empresarial e sustentabilidade para a gestão empresarial, 2013. Disponível em: $<\mathrm{http}$ ///www3.ethos.org.br/cedoc/responsabilidade-social-empresarial-e-sustentabilidade-para-a-gestao-empresarial/\#.WDLyNOYrK01>. Acesso em: 20 nov. 2016.

. Responsabilidade Social: Efeitos da Atuação Social na Dinâmica Empresarial (tese de doutorado), Departamento de Administração. São Paulo: USP, 2001.

BRASIL. Lei no ${ }^{\circ}$ 8.666, de 21 de junho de 1993. Disponível em: <http:// www.planalto .gov. br/ccivil_03/leis/L8666cons.htm>. Acesso em: 10 dez. 2016.

. Decreto 7.746 de 5 de junho de 2012, 2012a. Disponível em: <http://www. planalto. gov.br/ccivil_03/_ato2011-2014/2012/decreto/d7746.htm>. Acesso em: 12 set. 2016.

. Instrução Normativa 10, de 12 de novembro de 2012, 2012b. Disponível em: <http:// www.mma.gov.br/images/arquivo/80063/141112_IN10.pdf>. Acesso em: 18 out. 2016. 
DIAS, Tereza Cristina; MAGALHÃES, Elenice Maria; BARBOSA, Telma Regina C. G. Elementos que Influenciam o Planejamento Estratégico em Universidades: Um Estudo de Caso. In. Encontro de Administração Pública e Governança - EnAPG. Rio de Janeiro: ANPAD, 2006.

ELKINGTON, John. Canibais com Garfo e Faca. São Paulo: Makron Books, 2001.

FARIAS, Christiano Alves; NETO, João Zaleski; ZULIETTI, Luis Fernando; RUGGIERO, Sérgio. No limiar da quarta revolução industrial: Iniciativas para sustentabilidade por Empresas líderes do setor automotivo rumo à nova economia. Revista de Administração FACES, v. 2, no. 3, 2013.

GIL, Antonio Carlos. Como Elaborar Projetos de Pesquisa, 4. ed. São Paulo: Atlas, 2002. HOGAN, Daniel Joseph; MARANDOLA Jr., Eduardo; OJIMA, Ricardo. População e Ambiente. In: GOLDEMBERG, José (Coord.). Série Sustentabilidade. São Paulo: Blucher, 2010.

ICLEI. Manual Procura+ Um Guia para Implementação de Compras Públicas Sustentáveis, 3. ed. São Paulo: ICLEI Brasil, 2015.

KALINOWSKA, Anna; BATORCZAK, Anna. Universities for sustainability - new challenges from the perspective of the University of Warsaw. Environmental \& Socio-economic Studies, v. 3, n. 1, 2015.

LOZANO, Rodrigo. LOZANO, Francisco J.; MULDER, Karel; HUISINGH Donald; WAAS, Tom. Advancing higher education for sustainable development: international insights and critical reflections. Jornal of Cleaner Production, v. 48, 2013.

MEIRELLES, Hely Lopes. Direito administrativo brasileiro, 30. ed. São Paulo: Malheiros, 2005. MONZONI, Mario; BIDERMAN, Rachel; BETIOL, Luciana Stocco. Compras públicas sustentáveis como incentivo à inovação e à produção sustentável. Anais do IX Simpósio de Administração da Produção, Logística e Operações Internacionais - SIMPOI. 2006. FGV -EAESP. Disponível em: http://bibliotecadigital.fgv.br/dspace/ bitstream/handle/10438/15411/ Compras\%20P\%C3\%BAblicas\%20Sustent\%C3\%A1veis\%20como\%20Incentivo $\% 20 \%$ C3\%A0\%20

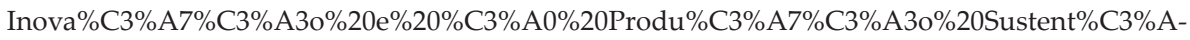
1vel.pdf? sequence=1\&isAllowed=y. Acesso em: 4 out. 2016.

NASCIMENTO, Thiago Gomes; CASTRO, Breno Giovanni Adaid; CARVALHO, Gabriel Porto; DEMO, Gisela. Valores organizacionais: uma análise Bibliométrica da produção nacional do período de 2000 a 2013 na área de administração. Revista Organizações em Contexto - online, v. 12, n. 24, 2016.

ODA, Marcel; MIRANDA, Zoraide Amarante Itapura de; ITANI, Alice; LICCO, Eduardo; KULAY, Luis Alexandre. Logística Sustentável: contribuição a processos de gestão. In Interfacehs: Revista de Gestão Integrada em Saúde do Trabalho e Meio Ambiente, v. 4, n. 1, 2009.

PNUMA. Programa das Nações Unidas para o Meio Ambiente. Rumo ao consumo sustentável na América Latina e Caribe. Publicação de base para o Workshop sobre Consumo Sustentável na América Latina e Caribe. São Paulo: Organização das Nações Unidas, 2001. Disponível em: www.pnuma.org/eficienciarecursos/documentos/conslacp.pdf. Acesso em: 16 nov. 2016.

POSNER, Stephen M.; STUART, Ralph. Understanding and advancing campus sustainability using systems framework. International Journal of Sustainability in Higher Education, v. 14, n. 3, 2013.

RIO+20. Conferência das Nações Unidas sobre Desenvolvimento Sustentável. Disponível em: <http://www.rio20.gov.br/sobre_a_rio_mais_20.html>. Acesso em: 12 set. 2016. 
SHARP, Leith. Higher education: the quest for the sustainable campus. Sustainability: Science, Practice \& Policy, v. 5, n. 1, 2009.

SILVA, Ricardo Cader da; BARKI, Teresa Villac Pinheiro. Compras públicas compartilhadas: a prática das licitações sustentáveis. Revista do Serviço Público. Brasília, v. 63, n. 2, 2012.

SOLLA, José (Org.). Relatório Rio+20: o modelo brasileiro: relatório de sustentabilidade da organização da Conferência das Nações Unidas sobre Desenvolvimento Sustentável. Brasília: FUNAG, 2012. Disponível em:http://www.rio20.gov.br/documentos/relatorio-rio-20.html. Acesso em: 12 set. 2016.

UFABC. Plano De Desenvolvimento Institucional (2013-2022), 2013. Disponível em: http:// pdi.ufabc.edu.br/wp-content/uploads/2013/ 06/PDI_UFABC_2013-2022.pdf. Acesso em: 27 nov. 2016.

. Plano de logística sustentável - PLS (2015-2022), 2015. Disponível em: http://propladi. ufabc.edu.br/images/PLS/pls_ufabc_2015.pdf. Acesso em: 9 ago. 2016.

. Relatório de Gestão - UFABC 2016, 2016. Disponível em: http://propladi.ufabc.edu. br/images/relatorio_gestao/relatorio_de_gestao_2015.pdf. Acesso em: 27 nov. 2016.

ULSF. Association of University Leaders for a Sustainable Future, 2008. Disponível em:http:// www.ulsf.org/about.html. Acesso em: 1ํ․ nov. 2016.

UNESCO. Organização das Nações Unidas para a Educação, a Ciência e a Cultura, 2016. Disponível em: http://www.unesco.org/new/pt/brasilia/about-this-office/single-view/news/ education_key_to_sustainability-1/. Acesso em: 1‥ nov. 2016.

UNIFESP. Plano de logística sustentável - PLS, 2015. Disponível em: <http:// www.unifesp. br/reitoria/dga/images/plano_de_gestao_logistica_sustentavel.pdf $>$. Acesso em: 9 ago. 2016.

Graduação em Números. 2016a. Disponível em: http://www.unifesp.br/reitoria/prograd/index.php/pro-reitoria-de-graduacao/informacoes-institucionais/graduacao-em-numeros. Acesso em: 27 nov. 2016.

Institucional - Apresentação, 2016b. Disponível em https://www. unifesp.br/institucional/institucionalsub/apresentacao. Acesso em: 27 nov. 2016.

VERGARA, Sylvia Constant. Projetos e Relatórios de Pesquisa em Administração, 16. ed. São Paulo: Atlas, 2016.

WEENEN, Hans Van. Towards a Vision of Sustainable University. International Journal of Sustainability in Higher Education, v. 1, n. 1, 2000.

YIN, Robert K. Estudo de caso: planejamento e métodos, 2. ed. Porto Alegre: Bookman, 2001.

Recebido em: 29-3-2017

Aprovado em: 28-08-2017

Avaliado pelo sistema double blind review.

Editor: Coordenação do PPGA/UMESP

Disponível em http://mjs.metodista.br/index.php/roc 